\title{
The neuropathological impact of COVID-19: a review
}

\author{
Ghadha Ibrahim Fouad* ${ }^{*}$
}

\begin{abstract}
Background: The Coronavirus disease 2019 (COVID-19) outbreak has become a challenging global issue after its emergence in December 2019. Due to the high adaptation of the virus, COVID-19 demonstrated a high transmission and infectivity potentials. Several studies demonstrated that severe acute respiratory syndrome coronavirus 2 (SARSCoV-2) induce deleterious neurological manifestations through interacting with the central nervous system (CNS).

Main body: The neuroinvasive potential of SARS-CoV-2 might contribute to its fatal behavior. Understanding the underlying mechanisms of this novel neuropathogen might contribute to the development of effective therapeutic strategies. The manifestations of neural damage in COVID-19 patients ranged from headache to severe encephalopathy and progression of preexisting neural disorders, it is speculated that neuroinvasion is strongly linked to the fatal respiratory dysfunction. The underlying neuropathological impact of emerging pneumonia (COVID-19) is still unclear.

Conclusion: This review demonstrated the urgent need to understand the neuropathology of COVID-19, to manage the current borderless viral outbreak of SARS-CoV-2 and its comorbidities. Moreover, SARS-CoV-2 could be regarded as an opportunistic neuropathogen that affects several vital functions in the human body.
\end{abstract}

Keywords: COVID-19, SARS-CoV-2, Neurological manifestations, Coronaviruses, Neuroinvasive potential

\section{Background}

Coronavirus disease 2019 (COVID-19)-associated respiratory dysfunction in the upper respiratory tract was first reported to $\mathrm{WHO}$ as pneumonia of unknown etiology in Hubei Province, Wuhan City, China, on December 31, 2019 (WHO 2020; Thompson 2020). China was the first hub for the spreading of this emerging viral outbreak of SARS-CoV-2, causing a global pandemic. This challenging pandemic hit 188 countries and resulted in a huge toll of confirmed death cases. By the third week of October, the total number of confirmed cases reached 41,074,593 in the entire world, with 1,128,532 deaths; these data were provided by the Center for Systems Science and Engineering (CSSE) at Johns Hopkins University (JHU) (CSSE 2020). There is limited knowledge about mechanisms of COVID-19 infections; in addition, there is no

\footnotetext{
*Correspondence: giffouad@nrc.sci.eg; ghadhaibrahim@yahoo.com Department of Therapeutic Chemistry, National Research Centre, 33 El-Bohouth St., Dokki, Cairo 12622, Egypt
}

effective therapeutic approach to manage this epidemic. Social distancing and lockdown in affected countries are the used strategies to limit the transmission of the viral infection.

The two most common and principal routes of transmission of SARS-CoV-2 are close contact with an asymptomatic carrier and respiratory virus-laden droplets. In addition, prolonged exposure to a high concentration of SARS-CoV-2 aerosols (exceeding the viral load) may contribute to the infection, especially in closed locations such as hospitals (Zhang et al. 2020). The principal route of SARS-CoV-2 transmission is the droplet contagion; the virus enters the intranasal and oral routes, infects the olfactory sensory neurons, and then invades the central nervous system (CNS) through the olfactory nerve; this explains the common sensory symptoms of hyposmia (a decreased sense of smell) and hypogeusia (a reduced ability to taste) (Li et al. 2020a). COVID-19 is a viral infection caused by severe acute respiratory syndrome coronavirus 2 (SARS-CoV-2). SARS-CoV-2 is a highly contagious and 
opportunistic virus that attacks the respiratory system. This infection ranged from asymptomatic infection (the incubation period) to respiratory failure, with clinical symptoms of headache, dry cough, and fever. The common clinical symptoms of COVID-19 include dry cough, fever, sore throat, dyspnea (shortness of breath), muscle soreness, fatigue, in addition to no notable improvement upon three days of treatment with antibiotics (Sun et al. 2020a). The case might get worse to acute respiratory distress syndrome (ARDS) that demands intensive care unit (Wang et al. 2020a) (Fig. 1). Moreover, SARS-CoV-2 demonstrated "extra-respiratory" actions in confirmed cases of COVID-19 (Lai et al. 2020), regarding the fact that coronaviruses are known to demonstrate symptoms of "multi-organ system damage" (Gulati et al. 2020). SARS-CoV-2 can attack several organs such as the heart, the liver, and the central nervous system (CNS). For example, some COVID-19 patients might suffer from a new-onset cardiac dysfunction (Paramasivam et al. 2020) or hepatic impairment (Wang et al. 2020b), or renal dysfunction (Li et al. 2020b). Politi et al. (2020) published the first report of human brain involvement in a COVID-19 patient. In addition, Moriguchi et al. (2020) reported a case of meningitis/encephalitis.

\section{Main text}

\section{What are coronaviruses (CoVs)?}

Coronaviruses (CoVs) are a large family of positivesense, single-stranded (ss) RNA viruses, spherical or oval shaped, with an average diameter of $100 \mathrm{~nm}$. CoVs possess surface spikes of viral membrane glycoproteins and demonstrate a typical crown-like shape by electron microscopy; the length of viral genome ranges between 26 and 32 kilobases (kb) (Schoeman and Fielding, 2019). Coronaviruses (CoVs) are classified into four genera, including $\alpha, \beta, \gamma, \delta$. " $\alpha$ - and $\beta$-" CoVs infect mammals, while " $\gamma$ - and $\delta$-" CoVs tend to infect birds. There are six identified CoVs as human-susceptible virus, among which $\beta$-CoVs, severe acute respiratory syndrome (SARS), and Middle East respiratory syndrome (MERS) lead to severe respiratory tract infections (Yin and Wunderink, 2018). SARS-CoV-2 is the seventh known CoV that can infect humans (Corman et al. 2019). SARS$\mathrm{CoV}-2$ was recognized as a $\beta$-coronavirus, that belongs to (subgenus Sarbecovirus, Orthocoronavirinae subfamily, Coronaviridae family), with $96.2 \%$ sequence homology with SARS-like coronavirus (bat-SL-CoVZC45), referring "bat" as the original host (Zhu et al. 2020; Guo et al. 2020; Lu et al. 2020). It was suspected that the bat is the natural and transmitting of SARS-CoV-2, regarding its similarity with SARS-CoV (Zheng 2020). The viral genome of CoVs encodes four main structural proteins to generate a structurally complete viral particle: the envelope (E) protein, membrane $(\mathrm{M})$ protein, nucleocapsid $(\mathrm{N})$ protein, and the spike (S) protein (Schoeman and Fielding, 2019). The "S protein" facilitates viral entry into the host cell and enables the fusion between the viral and host cell membranes (Kirchdoerfer et al. 2016; Zheng 2020).

It is speculated that SARS-CoV-2 has been introduced to humans by an unknown intermediate host before its genetic modification to transport from human to human. The infections of CoVs were mainly enzootic (i.e., limited only to their natural animal hosts) in birds and mammals. However, there is a sweeping deviation in the infectivity potential of CoVs by crossing the animal-human species barrier and infects humans. This was demonstrated in the first outbreak of SARS in China 2003, which was transmitted to 37 countries, and the second outbreak of MERS in Saudi Arabia in 2012 that was transmitted to 27 countries (Schoeman and Fielding 2019). COVID-19 represents the third presentation of a highly pathogenic and large-scale epidemic SARS-CoV-2 into the human

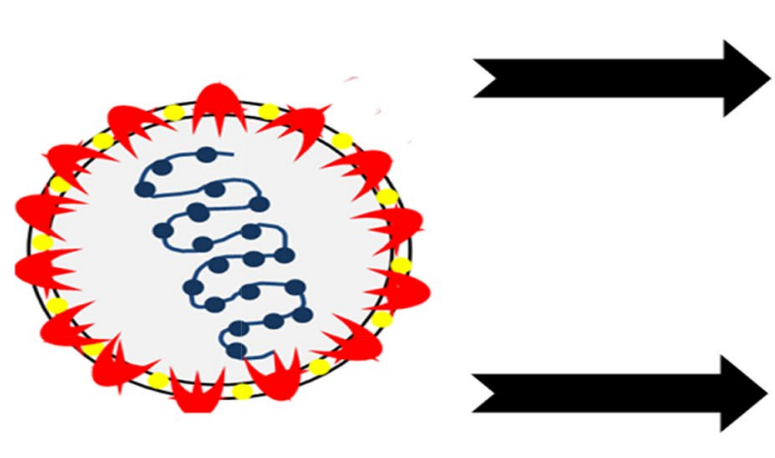

SARS-CoV-2
Mild symptoms (headache, hyposmia, hypogeusia, disturbed consciousness, and delirium)

\section{Severe symptoms (encephalopathy, respiratory dysfunction)}

Fig. 1 SARS-Cov-2 infection provokes mild symptoms and/or severe symptoms that could result in respiratory failure 
population. Moreover, this high pathogenicity of SARSCoV-2 might be ascribed to the asymptomatic infection of the virus that means that COVID-19 patients might transmit infection without the appearance of clinical symptoms, while tested positive for the presence of viral nucleic acids (Wang et al. 2020a); this could render the management of COVID-19 spreading more difficult.

\section{Neuropathological manifestations of COVID-19}

Human coronaviruses (CoVs) are characterized by high mortality rate along with their ease of transmission (Schoeman and Fielding 2019). Human CoVs could invade both the respiratory system and the CNS; this family of viruses is featured by that neuroinvasion and neurotropism (Desforges et al. 2020). Several researchers reported the potential of SARS-CoV-2 to attack the CNS and result in neurodegeneration (Moriguchi et al. 2020; Asadi-Pooya and Simani 2020; Toscano et al. 2020; Xiang et al. 2020). In the initial phases of SARS-CoV-2 infection of the respiratory system, olfactory tract is the principal route for virus entry to the brain and the CNS (Zhang et al. 2020). CoV can invade the brain via the olfactory tract in the early stages of infection within seven days (Desforges et al. 2020); CoV infects nasal cells, accesses the brain and cerebrospinal fluid (CSF) through the olfactory nerve and olfactory bulb, and induces neural damage (Wu et al. 2020a).

Neurological symptoms involved headache, impaired consciousness, seizures, acute cerebrovascular disease, hyposmia (a decreased sense of smell), hypogeusia (a reduced ability to taste), and neuralgias (Montalvan et al. 2020). The occurrence of COVID-19-associated neurodegeneration might reach $40 \%$ (Mao et al. 2020); this neural damage might be caused by direct infection, hypoxia, and immune response (Wu et al. 2020a). Patients with a mild infection may suffer from headache, disturbed consciousness, and delirium (Wu et al. 2020a); neurological damage was more common in COVID-19 patients with severe infection (Lai et al. 2020) who suffer from multiorgan failure (MOF) and hypoxia (Asadi-Pooya and Simani 2020). Moreover, COVID-19 patients might develop situation of impaired mental function (Nicholls and Peiris 2005). Toxic and viral encephalopathy may occur because of severe hypoxia and viremia (Guo et al. 2020); the risk of incidence of encephalopathy increases in patients with "preexisting" neurological disorder (Gulati et al. 2020). This infectious (viral)/acute encephalopathy signifies acute infection associated with hypoxia, metabolic disorders, and systemic inflammation, resulting in brain dysfunction (Young 2013; Tauber et al. 2017). Encephalitis indicates the existence of pathogen-induced neuroinflammation in the brain parenchyma, with common systems of headache, high temperature, and consciousness disorder (Ellul and Solomon 2018). SARS-CoV-2 could be detected in CSF, using genome sequencing, and thus increased the possibility of viral encephalitis (Hung et al. 2003; Xiang et al. 2020). Postmortem examinations of the brain of COVID-9 patients have revealed partial neurodegeneration, tissue congestion, and edema (Wu et al. 2020a). There is a possible link between the neuroinvasive potential of this pathogen and the respiratory failure of COVID-19 (Li et al. 2020c). Additionally, CoVs can invade the CNS, where they may either induce neurodegeneration or remain latent (Matías-Guiu et al. 2020), regarding that if a virus gets in the CNS, it is difficult to get out (Reinhold and Rittner 2017). There could be a strong connection between the SARS-CoV-2 infection of the brain stem and the respiratory dysfunction, considering that the brain stem controls vital functions including respiration and maintenance of blood pressure; it was found that SARS-CoV-2 could infect brainstem through a synapse-connected route from the lungs (Zhang et al. 2020). From this perspective, clinicians should perform an early evaluation of COVID-19 patients for neurological symptoms to manage the COVID-19-associated neurological manifestations and prevent the development of viral infection into a neurodegenerative disorder (Wu et al. 2020a). Accordingly, there is an urgent need to perform "follow-up studies" in COVID-19-recovered patients, as well as to provide spiritual and medical support for this kind of patients, to assess both the mental status and the general health condition. Thus, psychiatric and psychological issues (e.g., cognitive rehabilitation) should be considered in both patients and medical staff (Balachandar et al. 2020), to mitigate the COVID19-associated depression and stress ( $\mathrm{Li}$ et al. 2020c; Politi et al. 2020). Therefore, more research is required to understand the neuroinvasion capacity of the virus and to prevent the neuropathological impact of COVID-19 in recovered patients (Balachandar et al. 2020).

\section{The neuropathogenic mechanism of COVID-19:}

The mechanism underlying the neuropathogenesis of COVID-19 might be attributed to three factors: the first factor is the occurrence of hypoxia (due to alveolar gas exchange disorders) to the brain. The SARS-COV2 -associated respiratory dysfunction could cause severe pneumonia that leads to systemic hypoxia, and the generation of toxic metabolites, due to increased anaerobic metabolism in the brain mitochondria, that finally results in brain interstitial edema, obstruction of cerebral blood flow (CBF), headache, and even a coma (Tu et al. 2020). Hypoxia might contribute to the development of the acute cerebrovascular disease such as acute ischemic stroke (Wu et al. 2020a). It was demonstrated that COVID-19 patients often suffer from severe hypoxia 
(Guo et al. 2020), which may cause subsequent neural damage (Fig. 2).

The second factor involves the interaction of immune response due to the high influx of inflammatory mediators and cytokines (e.g., interleukin 6) and the activation of macrophages and T-lymphocytes, thus promoting neuroinflammation (Mehta et al. 2020; Wu et al. 2020a). This might be attributed to the neurotropic nature and neuroinvasive potential of some viruses including human CoVs that result in activation of microglia, macrophages, or astrocytes in the nervous system (Soung and Klein
2018; Asadi-Pooya and Simani 2020). This neurotropic nature of this opportunistic pathogen might enhance a pro-inflammatory state ( $\mathrm{Li}$ et al. 2004). Moreover, increased inflammatory cytokines and reduced lymphocytes are strongly correlated with the severity and progression of CoVs infection, including COVID-19 (Zhang et al. 2020). The SARS-COV-2-associated pneumonia is often linked to induced hyper-cytokinemia "cytokine storm" that result in generation of "hyper-inflammatory state" through uncontrolled over-production of multiple inflammatory cytokines and finally resulting in ARDS

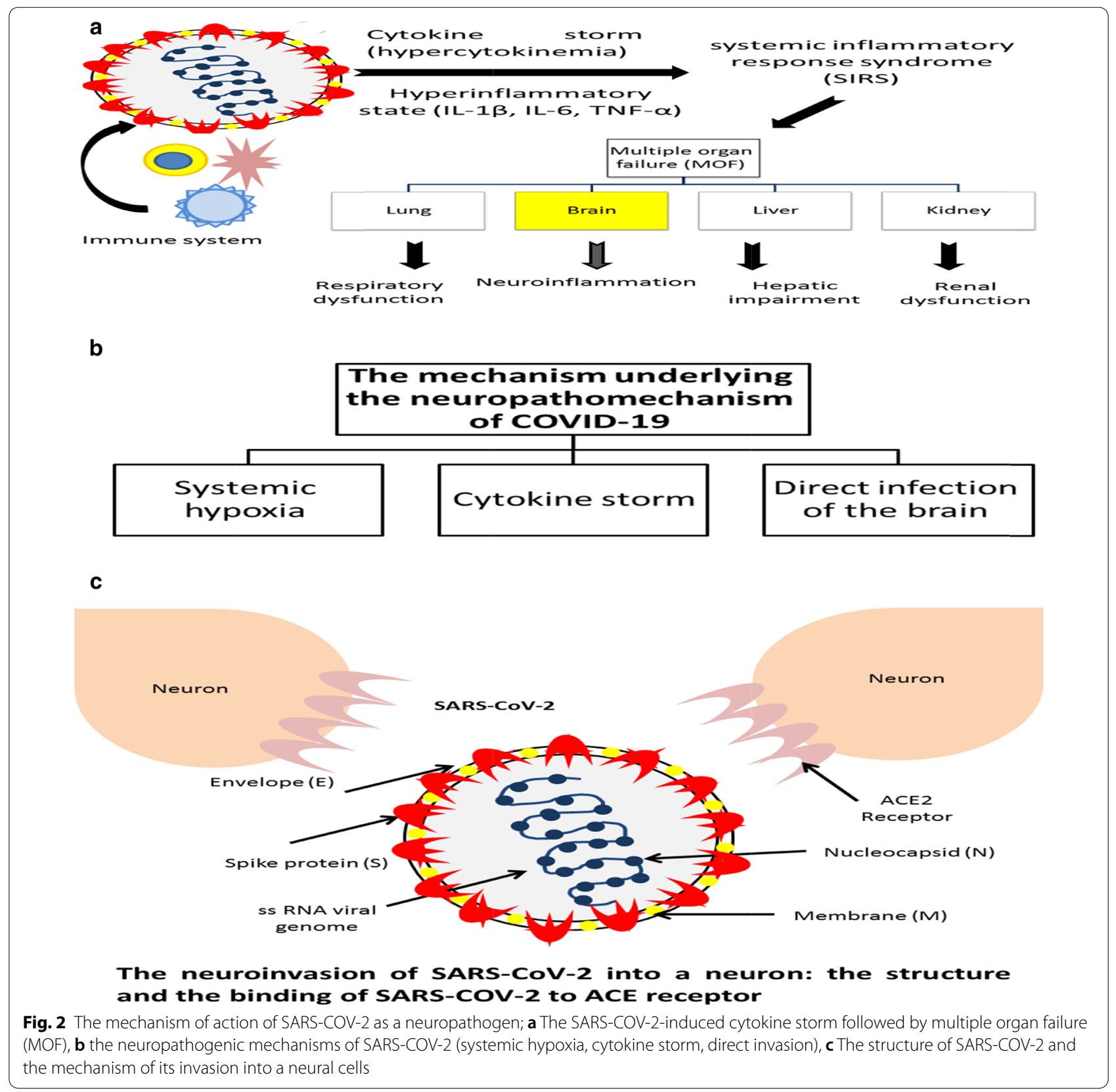


(Sun et al. 2020b). Therefore, this SARS-COV-2-induced systemic inflammatory response syndrome (SIRS) is a major player in the severity and mortality from this viral infection (Sun et al. 2020b). SIRS-mediated generation of free radicals and pro-inflammatory cytokines affects the microcirculation of the central and peripheral nervous system (Polidoro et al. 2020). Moreover, this "hyperinflammatory state" might be strongly related to multiple organ failure (MOF) through resulting in auto-immunity as the high levels of inflammatory cytokines can attack other tissues (Science Mag 2020).

This phenomenon of "cytokine release syndrome (CRS)" can activate the endothelial cells and result in endothelial dysfunction and induce coagulopathy (Hay et al. 2017) and formation of blood clots that can break apart and deposit in the lungs, resulting in fatal "pulmonary embolism" or the brain and resulting in "stroke" in COVID-19 patients (Klok et al. 2020). This might be attributed to the abundance of angiotensin-converting enzyme 2 (ACE2) receptors in the endothelium and the blood lining (Klok et al. 2020).

CoVs infection (e.g., SARS and COVID-19) might be implicated in the development of a systemic inflammatory response syndrome (SIRS) that could be linked to multiple organ failure (MOF) (Wu et al. 2020b). COVID19 patients might suffer from several endocrine and metabolic disruptions (e.g., hypo-/hyper-natremia, hypo-/ hyper-glycemia) and affect several organs causing kidney dysfunction, hepatic injury, and encephalopathy (Zubair et al. 2020). In severe COVID-19 patients, CRS participates to "toxic-metabolic encephalopathy" along with metabolic disruptions (Zubair et al. 2020).

Due to sequence homology with SARS-CoV, SARS$\mathrm{CoV}-2$ might simulate the behavior of SARS and MERS and induce neurodegeneration in the respiratory center in the medulla via enhancing the release of multiple inflammatory cytokines IL-1, IL-6, and TNF- $\alpha$ (Montalvan et al. 2020), regarding that IL-6 is strongly associated with the severity of viral infection (Wan et al. 2020). This CRS of SARS-CoV-2 infection is currently linked to the occurrence of acute cerebrovascular disorder (Huang et al. 2020; Chen et al. 2020; Mehta et al. 2020). One recent case report described Guillain-Barré syndrome (GBS), an immune-mediated neurological disorder, in COVID-19 patient, the neurological symptoms began two weeks after infection with SARS-COV-2 (Sedaghat and Karimi 2020); this demonstrated the potential of SARS-COV-2 to enhance auto-immunity, as the virus induces CRS and the uncontrolled cytokines attack the intact organs. Moreover, it has been assumed that SARS-CoV-2 might contribute to the alteration of the immune response of patients with multiple sclerosis (MS); this interaction might present a potential relation between SARS-CoV-2 and MS (Duffy and O'Reilly 2016). Moreover, viral infection-associated immune response could result in elevated serum levels of pro-inflammatory cytokines that result in skeletal muscle damage in COVID-19 patients (Ahmad and Rathore 2020).

The third factor is the direct infection of the brain; neuroinfections starts when SARS-CoV-2 passed through the nasal cavity, followed by the olfactory nerve, and finally the virus gained entry to the brain (Koyuncu et al. 2013). Using electron microscope, neurons were found to have viral particles entrapped in dilated vesicles (Zubair et al. 2020). Actually, the viral genome and proteins of some viruses could be detected in CSF or brain, indicating that viruses can directly invade the nervous system and cause neural damage (Koyuncu et al. 2013; Leber et al. 2016). It was evidenced that CoVs can penetrate the brain by spillage from the lungs into the blood "systemic vascular dissemination" or by trans-neuronal passage from nerve endings in the nasal epithelium or through spreading from airway receptors to "medullary cardio-respiratory centers" (Desforges et al. 2020; Natoli et al. 2020). Another suggested mechanism of infection, known as "Trojan horse mechanism," demonstrated that viral particles could infect immune cells (e.g., leukocytes), which causes systemic inflammation and disrupts the permeability of the blood-brain barrier (BBB) and allows the entry of more infected cells or even the virus particles into the brain (Zubair et al. 2020). This factor was supported by the fact that about $90 \%$ of COVID-19 patients could not breathe and might demonstrate neurological manifestations, such as headache, seizure, and impaired consciousness; this neuroinvasive capacity of SARS-CoV-2 might contribute to the fatal respiratory failure ( $\mathrm{Li}$ et al. 2020c). Furthermore, this explains why some infected patients demonstrate clear neurological symptoms such as cerebrovascular complications that could get worse into respiratory failure, and why other do not (Li et al. 2020a). Older COVID-19 patients, who developed cerebrovascular disorder, possess high levels of D-dimer and C-reactive protein (CRP) and are at a hyper-coagulation condition (Zubair et al. 2020).

In addition, the circulating viral RNA in the plasma might directly infect the endothelial cells of BBB ( $\mathrm{Li}$ et al. 2020c). It was demonstrated that SARS-CoV-2 infection might affect the endothelial cells and result in "systemic vascular endotheliitis" that enhance disruption of vascular homoeostasis, vasoconstriction, organ ischemia, and edema, and might create a "pro-coagulate state"; this endotheliitis might be involved in the occurrence of cerebrovascular stroke and coagulopathy (Román et al. 2020; Varga et al. 2020). Viral infection of SARS-CoV-2 might increase the incidence of "thromboembolism" in association with hypoxia and intravascular coagulation (Román 
et al. 2020). Strokes, either ischemic or hemorrhagic, are regarded as complications of SARS-CoV-2; binding of SARS-CoV-2 to ACE2 enhances arterial hypertension that could cause "intracerebral hemorrhage" (Guan et al. 2020) (Fig. 1).

\section{Interaction of SARS-CoV-2 and angiotensin-converting enzyme 2 (ACE2)}

In this review, we demonstrate the possible neuropathogenic route by which SARS-CoV-2 may penetrate based on previous researches of other respiratory viruses such as SARS and MERS (Li et al. 2012, 2016); COVID-19-associated pneumonia shares similar pathogenesis with that of SARS or MERS (Song et al. 2019). SARS-CoV-2 shares "sequence homology" with SARS-CoV and a bat coronavirus (Gorbalenya et al. 2020); the "genetic similarity" between SARS-CoV-2 and its cousin SARS-CoV reached $79.5 \%$, while its similarity to bat-coronavirus is 96\% (Wu et al. 2020b). However, SARS-CoV-2 is characterized by the nucleotide alterations in the spike (S) protein and its receptor-binding domain (RBD) (Kannan et al. 2020). Moreover, SARS-CoV-2 uses the same receptor as SARS-CoV for viral invasion into human host cells (Li et al. 2020c). Due to the common features and high sequence homology between SARS-CoV and SARS-CoV-2, SARS-CoV-2 might exhibit the same invasion potential ( $\mathrm{Li}$ et al. 2020c), through using the same cellular receptor (ACE2), which facilitates the entry of SARS-CoV-2 into human host cells. The high expression and notable abundance of ACE2 in almost organs including lungs, lung parenchyma, vascular endothelia, brain, and endothelial cells facilitate the spreading of circulating SARS-CoV-2 via the circulatory system (Hamming et al. 2004). This supports the deleterious effects of SARS$\mathrm{CoV}-2$ on whole body systems and its involvement in MOF, despite the fact that the lung is "the principal battle zone" (Zhang et al. 2020). The increased expression of ACE2 in the respiratory tract facilitates entry of SARSCoV-2 (Rothan and Byrareddy 2020). Once in the systemic circulation, the neurotrophic SARS-CoV-2 invades the neural tissue, where it binds with ACE2 receptors in the endothelium of capillaries (Baig et al. 2020). More interestingly, ACE2 is highly expressed in the two main regions responsible for the regulation of the respiratory cycle, ventrolateral medulla, and the nucleus of the tractus solitarius (Montalvan et al. 2020); the expression of ACE2 marks tissues susceptible to viral infection. A study by Netland et al. (2008) showed that the olfactory nerve was the main invasion route for the virus to invade the brain of SARS-CoV-infected transgenic mouse model of human ACE2. SARS-CoV-2 invades the host cells via direct interaction of its spike, a surface glycoprotein, with ACE2 (Gheblawi et al. 2020; Li 2016). Actually, after interacting with ACE2 in the endothelium of cerebral blood vessels, SARS-CoV-2 could result in disruption of $\mathrm{BBB}$, thereby disrupting the permeability of $\mathrm{BBB}$, facilitating the viral neuroinvasion into CNS; in addition, the ACE2 abundance in the brain enhances the neuroinfections (Li et al. 2020d; Mao and Jin, 2020). Moreover, the high pathogenicity and powerful spreading potential of SARS-CoV-2 might be attributed to the high binding affinity of the spike protein surface unit 1 to ACE2 (Wrapp et al. 2020; Zou et al. 2020) (Fig. 2).

\section{Future research and directions}

Currently, there are no FDA-approved drugs for COVID19 ; it is vital to find antiviral drugs or virucidal agents or vaccines to treat this novel viral infection. Several antiviral drugs are regarded as possible candidates (Guo et al. 2020). COVID-19 patients should receive antiviral drugs or virucidal agents to modulate the immune response (Li et al. 2020c; Zhang et al. 2020). Therefore, to design a therapeutic strategy for COVID-19 patient, it is mandatory to provide symptomatic treatment, to assess the vital functions of different organs, and to receive the required care. These precautions aimed at breaking this vicious circle of infection to reduce the risk of inflammatory events and promote the outcomes. Besides, the neuroinvasive potential and the neurotropic nature of SARS-CoV-2 should be investigated to apply an effective therapeutic approach that targets the molecular disruption of the neural system. Socially, it is mandatory to prepare the public awareness for the emergence of future pandemics and to develop virus prevention measures including social distancing, smart working, and promoting hygienic manners and to delay the onset of outbreaks and the incidence of the peak.

\section{Conclusion}

The neurological manifestations appeared in the severe cases of viral infection of SARS-CoV-2; however, we could assume that neurological manifestations might start from the incubation period of the viral infection in the form of headache, dizziness, and alterations in mental status. To sum it all up, there could be notable neurochemical interplay between SARS-CoV-2 and CNS. Therefore, careful clinical assessment of the patient should involve the neurological manifestations, particularly those hospitalized patients, to alleviate the potential mortality of neuroinfection-associated respiratory failure. There is still relatively limited availability of data about several aspects of COVID-19 to enable tackling the disease. Defining the COVID-19-associated neurological disorders is of the greatest importance to design an effective therapeutic approach, which targets the neurotropic nature of SARS-CoV-2, for neuroprotection. 


\section{Abbreviations}

COVID-19: Coronavirus disease 2019; SARS: Severe acute respiratory syndrome; MERS: Middle East respiratory syndrome; WHO: World Health Organization; CNS: Central nervous system; ARDS: Acute respiratory distress syndrome; CoVs: Coronaviruses; CSF: Cerebrospinal fluid; SIRS: Systemic inflammatory response syndrome; MOF: Multiple organ failure; CRS: Cytokine release syndrome; ACE2: Angiotensin-converting enzyme 2; TNF-a:Tumor necrosis factor alpha; IL-6: Interleukin 6; GBS: Guillain-Barré syndrome; MS: Multiple sclerosis; BBB: Bloodbrain barrier; CRP: C-reactive protein.

\section{Acknowledgments}

The author acknowledges all the researchers and the investigators whose work was the cornerstone for this review article.

\section{Authors' contributions}

The corresponding author wrote and approved the final manuscript.

\section{Funding}

Not applicable.

\section{Availability of data and materials}

Not applicable.

\section{Ethics approval and consent to participate}

Not applicable.

\section{Consent for publication}

Not applicable.

\section{Competing interests}

The author declares that there are no competing interests.

Received: 8 September 2020 Accepted: 22 December 2020

Published online: 12 January 2021

\section{References}

Ahmad I, Rathore FA (2020) Neurological manifestations and complications of COVID-19: a literature review. J Clin Neurosci 77:8-12. https://doi. org/10.1016/j.jocn.2020.05.017

Asadi-Pooya AA, Simani L (2020) Central nervous system manifestations of COVID-19: a systematic review. J Neurol Sci 413:116832. https://doi. org/10.1016/j.jns.2020.116832

Baig AM, Khaleeq A, Ali U, Syeda H (2020) Evidence of the COVID-19 virus targeting the CNS: tissue distribution, host-virus interaction, and proposed neurotropic mechanisms. ACS Chem Neurosci 11(7):995-998. https://doi. org/10.1021/acschemneuro.0c00122

Balachandar V, Mahalaxmi I, Subramaniam M et al (2020) Follow-up studies in COVID-19 recovered patients - is it mandatory? Sci Total Environ 729:139021. https://doi.org/10.1016/j.scitotenv.2020.139021

Chen C, Zhang XR, Ju ZY, He WF (2020) Advances in the research of cytokine storm mechanism induced by Corona Virus Disease 2019 and the corresponding immunotherapies. Zhonghua Shao Shang Za Zhi 36:E005

Corman VM, Lienau J, Witzenrath M (2019) Coronaviren als Ursache respiratorischer Infektionen [Coronaviruses as the cause of respiratory infections]. Internist (Berl) 60(11):1136-1145. https://doi.org/10.1007/s0010 8-019-00671-5

COVID-19 Dashboard by the Center for Systems Science and Engineering (CSSE) at Johns Hopkins University (JHU) (2020) https://coronavirus.jhu. edu/map.html. Accessed on 22 Oct 2020

Desforges M, Le Coupanec A, Dubeau P et al (2020) Human coronaviruses and other respiratory viruses: underestimated opportunistic pathogens of the central nervous system? Viruses 12:14

Duffy L, O'Reilly SC (2016) Toll-like receptors in the pathogenesis of autoimmune diseases: recent and emerging translational developments. Immunotargets Ther 5:69-80. https://doi.org/10.2147/ITT.S89795

Ellul M, Solomon T (2018) Acute encephalitis_diagnosis and management. Clin Med (Lond) 18(2):155-159. https://doi.org/10.7861/clinmedici ne.18-2-155
Gheblawi M, Wang K, Viveiros A et al (2020) Angiotensin-converting enzyme 2: SARS-CoV-2 receptor and regulator of the renin-angiotensin system: celebrating the 20th anniversary of the discovery of ACE2. Circ Res 126(10):1456-1474. https://doi.org/10.1161/CIRCRESAHA.120.317015

Gorbalenya, AE, Baker SC, Baric RS, de Groot RJ, et al (2020) Severe acute respiratory syndrome-related coronavirus: the species and its viruses-a statement of the Coronavirus Study Group. Nat Microbio

Guan WJ, Ni ZY, Hu Y et al (2020) Clinical characteristics of coronavirus disease 2019 in China. N Engl J Med 382(18):1708-1720. https://doi.org/10.1056/ NEJMoa2002032

Gulati A, Pomeranz C, Qamar Z et al (2020) A Comprehensive Review of manifestations of novel coronaviruses in the context of deadly COVID-19 global pandemic. Am J Med Sci 360(1):5-34. https://doi.org/10.1016/j. amjms.2020.05.006

Guo YR, Cao QD, Hong ZS, Tan YY, Chen SD et al (2020) The origin, transmission and clinical therapies on coronavirus disease 2019 (COVID-19) outbreakan update on the status. Mil Med Res 7(1):11

Hamming I, Timens W, Bulthuis ML, Lely AT, Navis G, van Goor H (2004) Tissue distribution of ACE2 protein, the functional receptor for SARS coronavirus. A first step in understanding SARS pathogenesis. J Pathol 203(2):631-637. https://doi.org/10.1002/path.1570

Hay KA, Hanafi LA, Li D et al (2017) Kinetics and biomarkers of severe cytokine release syndrome after CD19 chimeric antigen receptor-modified T-cell therapy. Blood 130(21):2295-2306. https://doi.org/10.1182/blood-201706-793141

Huang C, Wang Y, Li X et al (2020) Clinical features of patients infected with 2019 novel coronavirus in Wuhan, China [published correction appears in Lancet. 2020 Jan 30]. Lancet 395(10223):497-506. https://doi org/10.1016/S0140-6736(20)30183-5

Hung EC, Chim SS, Chan PK et al (2003) Detection of SARS coronavirus RNA in the cerebrospinal fluid of a patient with severe acute respiratory syndrome. Clin Chem 49(12):2108-2109. https://doi.org/10.1373/clinc hem.2003.025437

Kannan S, Shaik Syed Ali P, Sheeza A, Hemalatha K (2020) COVID-19 (Novel Coronavirus 2019)—recent trends. Eur Rev Med Pharmacol Sci 24(4):2006-2011. https://doi.org/10.26355/eurrev_202002_20378

Kirchdoerfer RN, Cottrell CA, Wang N et al (2016) Pre-fusion structure of a human coronavirus spike protein. Nature 531(7592):118-121. https://doi. org/10.1038/nature17200

Klok FA, Kruip MJHA, van der Meer NJM et al (2020) Incidence of thrombotic complications in critically ill ICU patients with COVID-19. Thromb Res 191:145-147. https://doi.org/10.1016/j.thromres.2020.04.013

Koyuncu OO, Hogue IB, Enquist LW (2013) Virus infections in the nervous system. Cell Host Microbe 13(4):379-393. https://doi.org/10.1016/j. chom.2013.03.010

Lai CC, Ko WC, Lee PI, Jean SS, Hsueh PR (2020) Extra-respiratory manifestations of COVID-19. Int J Antimicrob Agents 56(2):106024. https://doi. org/10.1016/j.jiantimicag.2020.106024

Leber AL, Everhart K, Balada-Llasat JM et al (2016) Multicenter evaluation of BioFire FilmArray meningitis/Encephalitis panel for detection of bacteria, viruses, and yeast in cerebrospinal fluid specimens. J Clin Microbiol 54(9):2251-2261. https://doi.org/10.1128/JCM.00730-16

Li F (2016) Structure, function, and evolution of coronavirus spike proteins. Annu Rev Virol 3(1):237-261. https://doi.org/10.1146/annurev-virology$110615-042301$

Li Z, Liu T, Yang N et al (2020a) Neurological manifestations of patients with COVID-19: potential routes of SARS-CoV-2 neuroinvasion from the periphery to the brain [published online ahead of print, 2020 May 4]. Front Med. https://doi.org/10.1007/s11684-020-0786-5

Li Z, Wu M, Yao JW, Guo J, Liao X, Song SJ, Li JL, Duan GJ et al (2020b) Caution on kidney dysfunctions of COVID-19 patients. Med Rxiv. https://doi. org/10.1101/2020.02.08.20021212

Li YC, Bai WZ, Hashikawa T (2020c) The neuroinvasive potential of SARS-CoV2 may play a role in the respiratory failure of COVID-19 patients. J Med Virol. https://doi.org/10.1002/jmv.25728

$\mathrm{Li} \mathrm{H}$, Xue Q, Xu X (2020d) Involvement of the nervous system in SARS-CoV-2 infection. Neurotox Res 38:1-7. https://doi.org/10.1007/s12640-02000219-8

Li K, Wohlford-Lenane C, Perlman S, Zhao J, Jewell AK, Reznikov LR, GibsonCorley KN, Meyerholz DK, McCray PB Jr (2016) Middle East respiratory syndrome coronavirus causes multiple organ damage and lethal 
disease in mice transgenic for human dipeptidyl peptidase 4. J Infect Dis 213(5):712-722

Li Y, Fu L, Gonzales DM, Lavi E (2004) Coronavirus neurovirulence correlates with the ability of the virus to induce proinflammatory cytokine signals from astrocytes and microglia. JVirol 78(7):3398-3406. https://doi. org/10.1128/jvi.78.7.3398-3406.2004

LiYC, Bai WZ, Hirano N, Hayashida T, Hashikawa T (2012) Coronavirus infection of rat dorsal root ganglia: ultrastructural characterization of viral replication, transfer, and the early response of satellite cells. Virus Res 163(2):628-635

Lu R, Zhao X, Li J et al (2020) Genomic characterisation and epidemiology of 2019 novel coronavirus: implications for virus origins and receptor binding. Lancet 395(10224):565-574. https://doi.org/10.1016/50140 $-6736(20) 30251-8$

Mao L, Wang MD, Chen SH, He QW, Chang J, Hong CD, Zhou YF, Wang D, Li YN, Jin HJ, Hu B (2020) Neurological manifestations of hospitalized patients with COVID-19 in Wuhan, China: a retrospective case series study. medRxiv. https://doi.org/10.1101/2020.02.22.20026500

Mao XY, Jin WL (2020) The COVID-19 pandemic: consideration for brain infection. Neuroscience 437:130-131. https://doi.org/10.1016/j.neuroscien ce.2020.04.044

Matías-Guiu J, Gomez-Pinedo U, Montero-Escribano P, Gomez-Iglesias P, Porta-Etessam J, Matias-Guiu JA (2020) Should we expect neurological symptoms in the SARS-CoV-2 epidemic. ¿Es esperable que haya cuadros neurológicos por la pandemia por SARS-CoV-2? Neurologia 35(3):170175. https://doi.org/10.1016/j.nrl.2020.03.001

Mehta P, McAuley DF, Brown M et al (2020) COVID-19: consider cytokine storm syndromes and immunosuppression. Lancet 395(10229):1033-1034. https://doi.org/10.1016/S0140-6736(20)30628-0

Montalvan V, Lee J, Bueso T, De Toledo J, Rivas K (2020) Neurological manifestations of COVID-19 and other coronavirus infections: a systematic review. Clin Neurol Neurosurg 194:105921. https://doi.org/10.1016/j.cline uro.2020.105921

Moriguchi T, Harii N, Goto J et al (2020) A first case of meningitis/encephalitis associated with SARS-Coronavirus-2. Int J Infect Dis 94:55-58. https://doi. org/10.1016/j.jijid.2020.03.062

Natoli S, Oliveira V, Calabresi P, Maia LF, Pisani A (2020) Does SARS-Cov-2 invade the brain? Translational lessons from animal models [published online ahead of print, 2020 Apr 25]. Eur J Neurol. https://doi.org/10.1111/ ene. 14277

Netland J, Meyerholz DK, Moore S, Cassell M, Perlman S (2008) Severe acute respiratory syndrome coronavirus infection causes neuronal death in the absence of encephalitis in mice transgenic for human ACE2. J Virol 82(15):7264-7275

Nicholls J, Peiris M (2005) Good ACE, bad ACE do battle in lung injury. SARS Nat Med 11(8):821-822. https://doi.org/10.1038/nm0805-821

Paramasivam A, Priyadharsini JV, Raghunandhakumar S, Elumalai P (2020) A novel COVID-19 and its effects on cardiovascular disease. Hypertens Res 43(7):729-730. https://doi.org/10.1038/s41440-020-0461-x

Politi LS, Salsano E, Grimaldi M (2020) Magnetic resonance imaging alteration of the brain in a patient with coronavirus disease 2019 (COVID-19) and anosmia. JAMA Neurol 77(8):1028-1029. https://doi.org/10.1001/jaman eurol.2020.2125

Polidoro RB, Hagan RS, de Santis Santiago R, Schmidt NW (2020) Overview: systemic inflammatory response derived from lung injury caused by SARS-CoV-2 infection explains severe outcomes in COVID-19. Front Immunol 11:1626. https://doi.org/10.3389/fimmu.2020.01626.

Reinhold AK, Rittner HL (2017) Barrier function in the peripheral and central nervous system-a review. Pflugers Arch 469(1):123-134. https://doi. org/10.1007/s00424-016-1920-8

Román GC, Spencer PS, Reis J et al (2020) The neurology of COVID-19 revisited: a proposal from the Environmental Neurology Specialty Group of the World Federation of Neurology to implement international neurological registries. J Neurol Sci 414:116884. https://doi.org/10.1016/j. jns.2020.116884

Rothan HA, Byrareddy SN (2020) The epidemiology and pathogenesis of coronavirus disease (COVID-19) outbreak. J Autoimmun 109:102433. https:// doi.org/10.1016/j.jaut.2020.102433

Schoeman D, Fielding BC (2019) Coronavirus envelope protein: current knowledge. Virol J 16(1):69. https://doi.org/10.1186/s12985-019-1182-0
Science Mag (2020) https://www.sciencemag.org/news/2020/04/how-doescoronavirus-kill-clinicians-trace-ferocious-rampage-through-body-brain -toes. Accessed 2 June 2020

Sedaghat Z, Karimi N (2020) Guillain Barre syndrome associated with COVID19 infection: a case report. J Clin Neurosci 76:233-235. https://doi. org/10.1016/j.jocn.2020.04.062

Song Z, XU Y, Bao L et al (2019) From SARS to MERS, thrusting coronaviruses into the spotlight. Viruses 11(1):59. https://doi.org/10.3390/v11010059

Soung A, Klein RS (2018) Viral encephalitis and neurologic diseases: focus on astrocytes. Trends Mol Med 24(11):950-962. https://doi.org/10.1016/j. molmed.2018.09.001

Sun P, Qie S, Liu Z, Ren J, Li K, Xi J (2020a) Clinical characteristics of hospitalized patients with SARS-CoV-2 infection: a single arm meta-analysis. J Med Virol. https://doi.org/10.1002/jmv.25735

Sun X, Wang T, Cai D et al (2020b) Cytokine storm intervention in the early stages of COVID-19 pneumonia. Cytokine Growth Factor Rev 53:38-42. https://doi.org/10.1016/j.cytogfr.2020.04.002.

Tauber SC, Eiffert H, Brück W, Nau R (2017) Septic encephalopathy and septic encephalitis. Expert Rev Anti Infect Ther 15(2):121-132. https://doi. org/10.1080/14787210.2017.1265448

Thompson R (2020) Pandemic potential of 2019-nCoV. Lancet Infect Dis 20(3):280. https://doi.org/10.1016/S1473-3099(20)30068-2

Toscano G, Palmerini F, Ravaglia S et al (2020) Guillain-Barré Syndrome associated with SARS-CoV-2. N Engl J Med 382(26):2574-2576. https://doi. org/10.1056/NEJMc2009191

Tu H, Tu S, Gao S, Shao A, Sheng J (2020) The epidemiological and clinical features of COVID-19 and lessons from this global infectious public health event. J Infect. https://doi.org/10.1016/j.jinf.2020.04.011

Varga Z, Flammer AJ, Steiger P et al (2020) Endothelial cell infection and endotheliitis in COVID-19. Lancet 395(10234):1417-1418. https://doi. org/10.1016/S0140-6736(20)30937-5

Wan SX, Yi QJ, Fan SB et al (2020) Characteristics of lymphocyte subsets and cytokines inperipheral blood of 123 hospitalized patients with 2019 novel coronavirus pneumonia (NCP). Med Rxiv 02(10):20021832

Wang D, Hu B, Hu C, Zhu F, Liu X, Zhang J, Wang B, Xiang H, Cheng Z, Xiong Y, Zhao Y, Li Y, Wang X, Peng Z (2020) Clinical characteristics of 138 hospitalized patients with 2019 novel coronavirus-infected pneumonia in Wuhan. China JAMA. https://doi.org/10.1001/jama.2020.1585

Wang Y, Liu S, Liu H, Li W, Lin F, et al. SARS-CoV-2 infection of the liver directly contributes to hepatic impairment in patients with COVID-19. J Hepatol 2020

WHO. Novel coronavirus (2019-nCoV) situation Report-1 (2020) https://www. who.int/docs/default-source/coronaviruse/situation-reports/20200121sitrep-1-2019-ncov.pdf?sfvrsn=20a99c10 4. Accessed 15 May 2020

Wrapp D, Wang N, Corbett KS et al (2020) Cryo-EM structure of the 2019-nCoV spike in the prefusion conformation. Science 367(6483):1260-1263. https ://doi.org/10.1126/science.abb2507

Wu Y, Xu X, Chen Z et al (2020a) Nervous system involvement after infection with COVID-19 and other coronaviruses. Brain Behav Immun 87:18-22. https://doi.org/10.1016/j.bbi.2020.03.031

Wu A, Peng Y, Huang B et al (2020b) Genome Composition and divergence of the novel coronavirus (2019-nCoV) originating in China. Cell Host Microbe 27(3):325-328. https://doi.org/10.1016/j.chom.2020.02.001

Xiang P, Xu XM, Gao LL, Wang HZ, Xiong HF et al (2020) First case of 2019 novel coronavirus disease with Encephalitis. China Xiv T202003:00015

Yin Y, Wunderink RG (2018) MERS, SARS and other coronaviruses as causes of pneumonia. Respirology 23(2):130-137. https://doi.org/10.1111/ resp.13196

Young GB (2013) Encephalopathy of infection and systemic inflammation. J Clin Neurophysiol 30(5):454-461. https://doi.org/10.1097/WNP.0b013 e3182a73d83

Zhang Y, Geng X, Tan Y et al (2020) New understanding of the damage of SARS-CoV-2 infection outside the respiratory system. Biomed Pharmacother 127:110195. https://doi.org/10.1016/j.biopha.2020.110195

Zheng J (2020) SARS-CoV-2: an emerging coronavirus that causes a global threat. Int J Biol Sci 16(10):1678-1685. https://doi.org/10.7150/ijbs.45053

Zhu N, Zhang D, Wang W et al (2020) A Novel coronavirus from patients with pneumonia in China, 2019. N Engl J Med 382(8):727-733. https://doi. org/10.1056/NEJMoa2001017 
Zou L, Ruan F, Huang M et al (2020) SARS-CoV-2 viral load in upper respiratory specimens of infected patients. N Engl J Med 382:1177-1179. https://doi. org/10.1056/NEJMc2001737

Zubair AS, McAlpine LS, Gardin T, Farhadian S, Kuruvilla DE, Spudich S (2020) Neuropathogenesis and Neurologic Manifestations of the Coronaviruses in the Age of Coronavirus Disease 2019: a review [published online ahead of print, 2020 May 29]. JAMA Neurol. https://doi.org/10.1001/jamaneurol .2020 .2065

\section{Publisher's Note}

Springer Nature remains neutral with regard to jurisdictional claims in published maps and institutional affiliations.

\section{Submit your manuscript to a SpringerOpen ${ }^{\odot}$ journal and benefit from:}

- Convenient online submission

- Rigorous peer review

- Open access: articles freely available online

- High visibility within the field

- Retaining the copyright to your article

Submit your next manuscript at $\boldsymbol{\nabla}$ springeropen.com 